\title{
Treatment of War-related Penetrating Brain Injury during Syrian Conflict: Importance of Debridement and Meticulous Closure
}

\author{
Hassan A. Al-Shatoury, MD, MHPE \\ Department of Neurosurgery, Faculty of Medicine, Suez Canal University, Egypt
}

\begin{abstract}
Background: Principles of treating war-related penetrating brain injury had been developed long time ago. Some neurosurgeons advocate the traditional surgical repair with thorough debridement and tight closure especially the dura. Other minimalists prefer simple wound closure. Aim: Presentation of 28 patients with penetrating brain injury who had been surgically treated during Syrian conflict. The author reviews related literature and compares between minimal and traditional approaches. Methods: A descriptive study of 28 patients who had been operated in North Syria during March-April 2013. Operative technique included thorough debridement, removal of accessible in-driven bone fragments and foreign bodies, hemostasis, watertight repair of the dura and scalp closure. Karnofsky score and Glasgow Outcome scale were used for outcome assessment. Results: We performed 30 operations in 28 patients ( 24 males / 4 females). Age was $22 \pm 15$ years (range 3-55). At admission, Glasgow Coma Score of 15-13 was (35.7\%), 12-9 was (21.4\%), and 8-3 was (42.9\%). Outcome evaluation after 1 month showed good recovery in (39.3\%), moderate recovery in (21.4\%), severe disability in (28.6\%), vegetative states in (3.6\%), and death in $2(7.1 \%)$. Complications were very minor (10.7\% superficial infection). Two patients needed reoperation; 1 for bullet removal and the other for evacuation of collected hematoma. Conclusion: Minimal brain debridement is more likely to require an additional debridement and may result in higher incidence of life-threatening CSF leak or fatal meningitis. Adequate debridement, removal of bone chips, foreign bodies, and tight closure of the dura should be performed in penetrating brain injury.
\end{abstract}

Keywords: Traumatic Brain Injury, Blast Injury, Cranial, War-related Injury

\section{Introduction}

Blasts may cause a full severity range of traumatic brain injury, from mild concussion to severe, even fatal penetrating injury. The injury magnitude depends on several factors, including velocity of the blast and its distance from the victim, the weight of the missile, and its materials ${ }^{(1)}$. Explosive blast brain injury has unique features such as early cerebral edema, and prolonged vasospasm that may be different from oth- er types of injuries ${ }^{(2)}$. The basic principles used in the management of blast and other war-related brain injuries were developed very early during the wars of the past century. During World War I, Harvey Cushing implemented en-block bone resection, suction debridement, magnet removal of metallic fragments, and tight dural and scalp closure that decreased mortality from $54 \%$ to $28 \%(3)$. These trends continued for decades, advocating thorough missile track debridement, meticulous dural closure to 
prevent cerebral spinal fluid (CSF) leakage and subsequent infection ${ }^{(4-7)}$. Brandvold et al., in long-term analysis of Israeli survivors found that $48 \%$ had retained in-driven intracranial bone and further questioned the need to aggressively remove all penetrating fragments ${ }^{(8)}$. The Iran-Iraq war also led to a wealth of published data, including reports on the causes of infections and the vascular complications of penetrating head injuries $^{(7,9,10)}$. Closed head injury data from bomb blasts in the Lebanon conflict, and later from the Iraq conflict emphasize the complexity of blast injuries, which combine the elements of both penetrating and blast effects $^{(11)}$.

More recently, some reports have appeared wherein wartime brain wounds have been treated by minimal brain debridement with little or no attention to tight dural closure. Many of these reports claimed that debridement would also affect partially devitalized adjacent brain tissue, and might have led to additional neurologic deficits or lesser degree of recovery of functions ${ }^{(8-10,12)}$. The aim of this paper is to present the experience with the management of a group of patients with warrelated penetrating brain injuries during the Syrian conflict in early 2013. The author also reviews related literature and compares between minimal and aggressive surgical management of these injuries.

\section{Patients and Methods}

This is a prospective study carried on in a hospital in a small town at North Syria. The hospital has a team of different medical specialties. This team consisted of the author as a single neurosurgeon, a general surgeon, vascular surgeon, orthopedic surgeon, and an anesthesiologist. Supporting and nursing staff were available and adequate regarding the number and qualification. The hospital was equipped with two operating rooms, 2-bed ICU, 25-bed ward,
X-ray imaging, laboratory, and pharmacy. The nearest available CT and MRI centers were around $30 \mathrm{Km}$ away. During MarchApril 2013, the author interviewed over 300 patients with neurological disorders. Sixtysix Patients had been operated for neurosurgical procedures. Among them, 28 patients had war-related penetrating brain injuries, for whom, 30 operations had been performed.

Clinical assessment: Advanced Trauma Life support (ATLS) ${ }^{(13)}$ principles guided initial assessment and resuscitation of all patients upon arrival to the hospital. Steps included acute control of airway, breathing, and circulation, prevention of hypoxia, prevention of hypotension, initial neurological evaluation (Glasgow Coma Scale, pupils, and focal deficits), assessment of cranium and face for external injury, evaluation of the spine, and concomitant head-to-toe evaluation for other life or limb-threatening injuries.

Radiological assessment: As the circumstance in Syria, at that time was very poor, patients before arriving to the hospital went first to the nearest $\mathrm{CT}$ center which was about $30 \mathrm{Km}$ away. The paramedic accompanied the patient in the ambulance recorded the $\mathrm{CT}$ images from the screen of the $\mathrm{CT}$ machine on his mobile phone (video recording) as there were no films available for printing. At the admission of the patient, the video recordings of the $\mathrm{CT}$ images were downloaded on the laptop of the author for assessment and further management. Image intensifier (C-Arm) was sometimes used for localization of foreign bodies. Assessment of $\mathrm{CT}$ images included the extent of brain injury, bone fractures, in-driven bone chips and presence of foreign bodies. The wound tract was readily visualized.

Inclusion/Exclusion criteria: All patients with war-related brain injuries had been operat- 
ed, except those with post-resuscitation GCS of $3-5^{(14)}$. In such situations, the conditions were explained to the relatives who were advised to go across the borders to Turkey for admission into ICU. Due to some political reasons, relatives sometimes preferred to transfer patients to Turkey, while the other refused.

\section{Initial medical treatment}

With evidences of brain herniation (e.g., unequal pupils, midline shift), bolus administration of mannitol was given provided the patient was hemodynamically stable. Loading dose of anticonvulsant phenytoin $(15 \mathrm{mg} / \mathrm{kg})$ was given to all patients with maintenance of $5-7 \mathrm{mg} / \mathrm{kg} / \mathrm{day}^{(15)}$. Broadspectrum antibiotic therapy was used immediately after admission. The rate of infection in penetrating head injury was expected to be high because of contamination from foreign objects, skin, hair, clothing, and bone fragments ${ }^{(16)}$.

Indications for surgery: The aim of surgical intervention was to do debridement of devitalized tissues, remove any hematoma, remove accessible in-driven bone fragments and foreign bodies, insure homeostasis, repair the dura tightly, and close the scalp without tension as much as we could.

Surgical Approach: All patients underwent full exploration of the wound and removal of all accessible foreign bodies and bone fragments, with debridement of contused brain and complete hemostasis. The dura was closed in a watertight fashion using a pericranium flap. Bone flap was placed after debridement. (Full description of surgical technique is present in the results section).

Postoperative management: All patients had been admitted to the ICU for further postoperative management. For patients who were intubated, a short-acting seda- tion was done using propofol to allow frequent neurological examination. ICP monitoring was not available; however, adequate oxygenation and blood pressure stability were insured.

Assessment of outcome: We used the Karnofsky scale ${ }^{(17)}$ to assess the outcome before discharge from the hospital. It was difficult to communicate again, with patients. SCF leak, postoperative wound infection, post-traumatic fits, and other expected complications were recorded.

\section{Results}

\section{Demographic data}

Twenty-eight patients were included in this study, 24 were males and 4 were females. The average age was $22 \pm 15$ with a range that varied from 3 to 55 years. The average time from trauma to hospital admission was 2:45 hours (range from 1:00 hour to 6:30 hours), including performing $\mathrm{CT}$ brain before admission. Hospital stay was $10.3 \pm 5.1$ days (range 3-22 days). Thirty surgical procedures were performed for these 28 patients. One patient had two-staged operation; one for debridement of the frontal entry, and the second for foreign body removal from the occipital site. The other patient had primary debridement and repair, followed by a second surgery for hematoma evacuation that had been recollected after few hours.

\section{Clinical presentation}

As assessed by GCS (8-3), 42.9\% of patients were in the category of severe traumatic brain injury (TBI), while $57.1 \%$ had mild or moderate TBI. Bleeding from penetrating site was apparent in all patients. Focal deficits, including aphasia or hemiparesis were present in $60.7 \%$. External herniation from penetrating site was present in $39.3 \%$. Fits occurred in $10.7 \%$. Other associated injuries were present in $46.4 \%$ of patients (Table 1 ). 
Table 1: Clinical presentations and other associated injuries

\begin{tabular}{|l|cc|}
\hline Presentation & Number & $\%$ \\
\hline GCS at admission: & 10 & 35.7 \\
- GCS 15-13 & 6 & 21.4 \\
- GCS 12-9 & 12 & 42.9 \\
- GCS 8-3 & 28 & 100 \\
Bleeding & 17 & 60.7 \\
Focal deficit & 11 & 39.3 \\
External brain herniation & 3 & 10.7 \\
Fits & & \\
Other associated injuries: & 7 & 25 \\
- Limb & 3 & 10.7 \\
- Abdominal & 2 & 7.1 \\
- Neck & 1 & 3.6 \\
- Rupture Eye globe & &
\end{tabular}

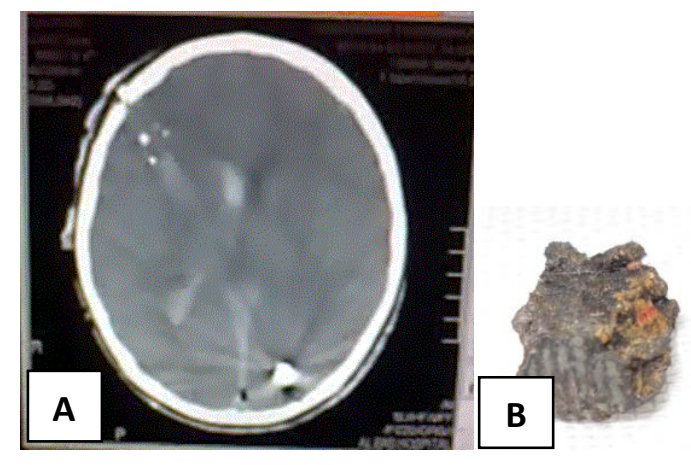

\section{Radiological study}

All patients had their CT-brain before reaching the hospital. A video recording was a simple method to transfer the images on the cell phone of the paramedics. Both soft tissues and bone window images were available. $100 \%$ of patients had in-driven bone fragments, 21 (75\%) had edema and a shift of the midline, 17 (60.7\%) had foreign bodies, $11(39.3 \%)$ had intraventricular hematomas, and 7 (25\%) had intracerebral hematomas. Figures 1 and 2 show examples of CT findings.
Figure 1: (A) CT scan from a male child aged 7-years old. Blast penetration was from right frontal area, with a track crossing the midline. The blast was located at left occipital area. Multiple in-driven bone chips were present at entry site, with intraventricular hemorrhage and brain contusion. This patient had two operations. The first was for debridement and closure of the frontal penetration, with trial to remove the foreign body at the same surgery at prone position. ICP was very high, so removal of the blast. $(B)$ was done 1 week later.
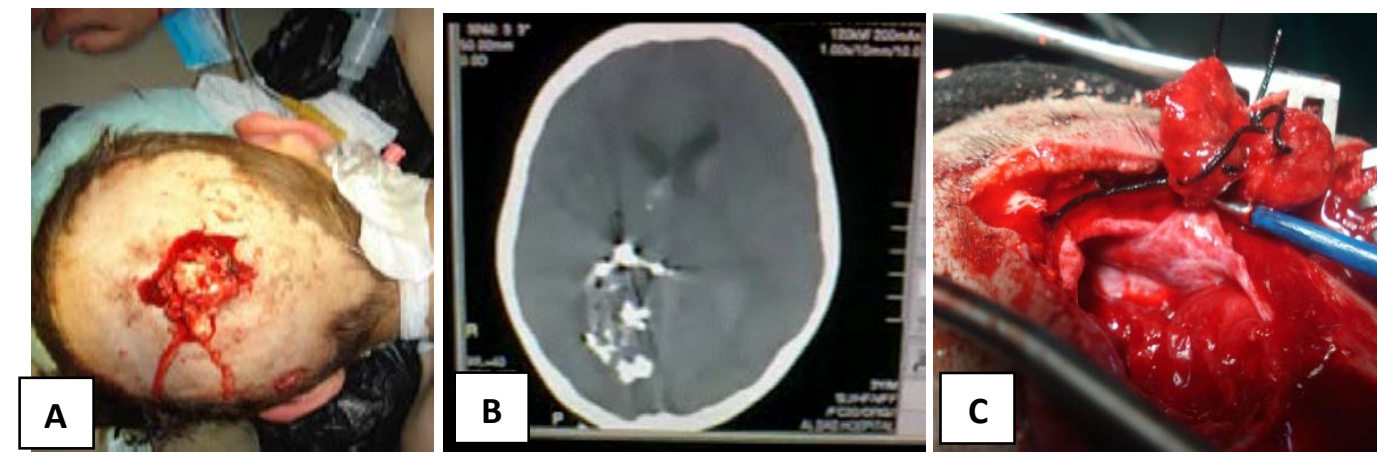

Figure 2: A male child aged 5-years old, had been injured by a blast. Brain was herniating from a paramedian occipital wound (A). CT brain shows in-driven bone chips and foreign bodies occupying the right occipital lob touching the midline (B). Wound exploration was done, with debridement and hemostasis. The superior sagittal sinus was intact $(C)$.

\section{Surgical technique}

After induction of general anesthesia, the patient was placed in the proper position that allowed adequate exposure of the wound and possible extension. Thorough gentle irrigation was used to flush out all tissues extruding from the wound site. In some patients, a traditional large trauma 
flap was used incorporating the entry site at its middle. Adequate exposure of the bony defect was essential, and all free bone fragments were removed. The underlying dural injury was often found to extend beyond the margins of the bone injury. The bone opening was extended until intact dura could be visualized.

Once the dura was exposed, herniated brain tissues often extruded from the dural defect. This was irrigated with normal saline. The tract of penetration through the brain was gently flushed with a $50 \mathrm{ml}$ syringe that allowed easy removal of indriven bone fragments. Any accessible foreign bodies as well as necrotic tissues, and blood clots were removed by gentle suction. Dural defect was sometimes extended to allow adequate debridement of the injured brain. Meticulous hemostasis was accomplished using bipolar coagulation, usually without the need to use of hemostatic agents. Dural repair was undertaken next. Watertight closure was always used, and it was important to reach the injured dural which usually lied beyond the fissured bone. Necrotic dural edge was removed, so that primary closure was usually difficult. A pericranium flap was the first choice to use, and it was usually helpful to put a one that was larger than the actual dural defect. This allowed for easy suture and provided extra space for the edematous brain to expand without the risk of herniation. Temporalis fascia was used in some cases.

Once dura was closed, the bone flap or fragments were replaced after debridement of contused parts. Sizeable bone fragments were chosen. Fixation was only available using silk sutures. A large suction drain was inserted (16 or 18), and the galea was closed with absorbable sutures. The scalp was then closed with nylon or silk. In some cases we used a rotational flap to cover the defect. The scalp closure serves as a crucial barrier in preventing infection (Figure 3, and Table 2).

Table 2: Steps done in 30 surgical procedures

\begin{tabular}{|l|cc|}
\hline Step & $\begin{array}{c}\text { Number } \\
\text { performed }\end{array}$ & $\%$ \\
\hline - Large trauma scalp flap & 16 & 53.3 \\
- Scalp incision in line with wound & 14 & 46.7 \\
- Craniotomy & 19 & 63.3 \\
- Craniectomy & 11 & 36.7 \\
- Contused brain debridement & 26 & 86.7 \\
- Foreign bodies removal & 16 & 53.3 \\
- Dural graft using pericranium & 16 & 53.3 \\
- Dural graft using temporalis fascia & 8 & 26.7 \\
- Rotational flap for the scalp & 9 & 30 \\
- Suction drain & 30 & 100 \\
\hline
\end{tabular}



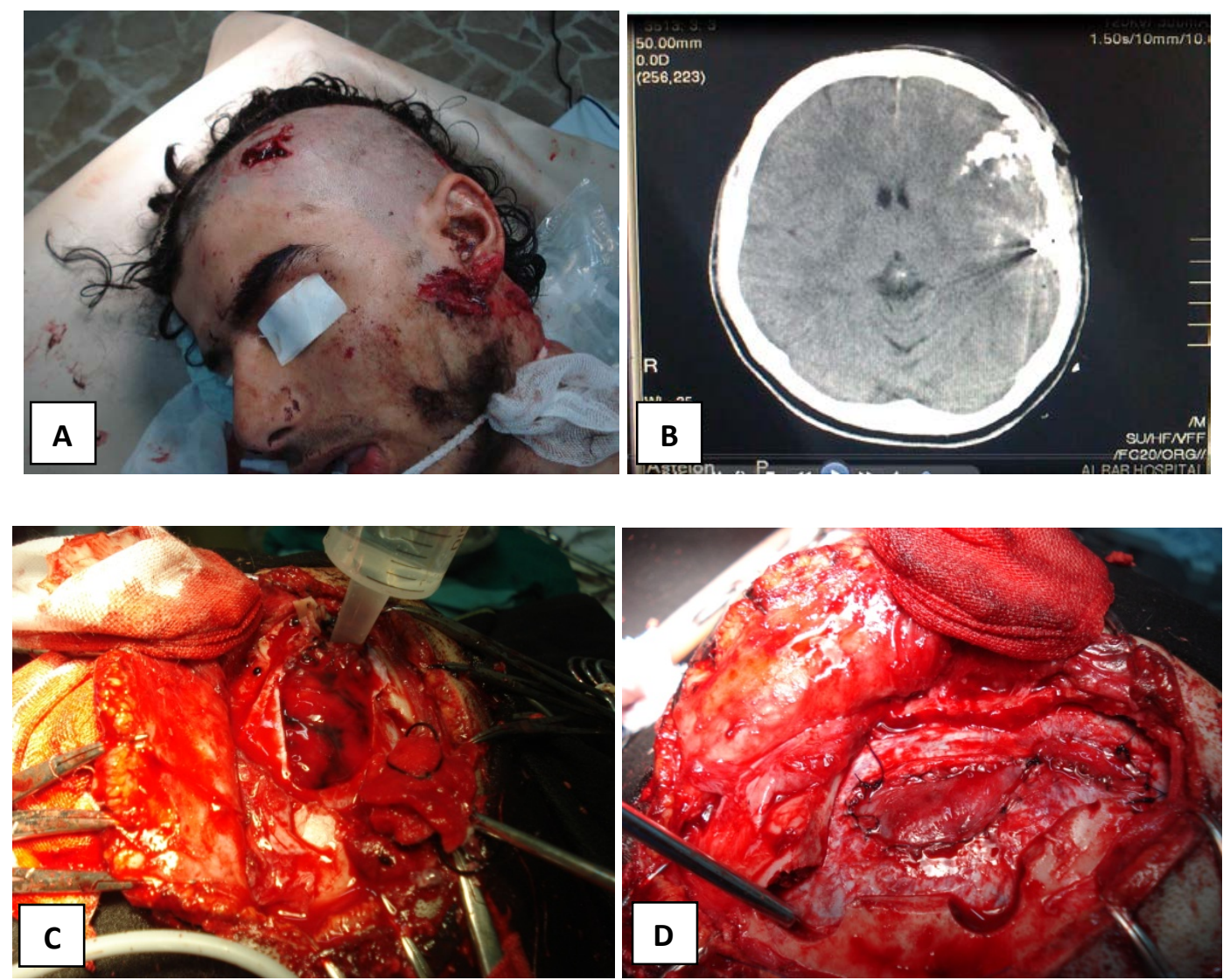

Figure 3: Surgical Technique: Male patient, aged 23-years-old had been hit by a penetrating blast injury. The entry site is very small as seen at the left frontal area (A). CT brain shows many in-driven bone fragments with some metals (causing artifact) (B). Large trauma flap was designed and craniotomy was done. Irrigation with $50 \mathrm{ml}$ syringe is a very simple method to remove bone chips (C). Meticulous dural repair using pericranium flap was done (D)

Table 3: Glasgow Outcome Scale Score

\begin{tabular}{|l|l|ll|}
\hline Score & Meaning & $\begin{array}{l}\text { No. pa- } \\
\text { tients }\end{array}$ \\
\hline 5 & Good recovery & 11 & 39.3 \\
4 & Moderate disability & 6 & 21.4 \\
3 & Severe disability & 8 & 28.6 \\
2 & Vegetative & 1 & 3.6 \\
1 & Dead & $2 *$ & 7.1 \\
& Total & 28 & \\
\hline
\end{tabular}

\begin{abstract}
*=One patient died from intracerebral hematoma that was evacuated by a second surgery. The other patient had sagittal sinus injury and developed venous infarction two days after surgery.
\end{abstract}

\section{Clinical Outcome}

The Glasgow Outcome Scale score showed $11(39.3 \%)$ patients to have a good recovery, $6(21.4 \%)$ with moderate disability, 8 (28.6\%) with severe disability, 1 (3.6\%) vegetative, and 2 (7.1\%) dead (Table 3). Karnofsky scale was also used for functional outcome assessment (Table 4). Table 5 shows reported complications. Three patients had a superficial wound infection. Late follow up was difficult because of difficulty to communicate with patients by phone or by visits. 

Table 4: Karnofsky Outcome score

\begin{tabular}{|c|l|cc|}
\hline Score & \multicolumn{1}{|c|}{ Meaning } & $\begin{array}{c}\text { No. pa- } \\
\text { tients }\end{array}$ & $\%$ \\
\hline 100 & Normal, no complaints & 0 & 0 \\
90 & Able to carry on normal activity, minor symptoms & 7 & 25 \\
80 & Normal activity with effort, some symptoms & 4 & 14.3 \\
70 & Cares for self, unable to carry on normal activity & 1 & 3.6 \\
60 & Requires occasional assistance, cares for most needs & 2 & 7.1 \\
50 & Requires considerable assistance and frequent care & 3 & 10.7 \\
40 & Disabled, requires special care and assistance & 5 & 17.9 \\
30 & Severely disabled, hospitalized & 2 & 7.1 \\
20 & Very sick, active supportive care needed & 2 & 7.1 \\
10 & Moribund, fatal are progressing rapidly & 0 & 0 \\
0 & Dead & $2^{*}$ & 7.1 \\
\hline
\end{tabular}

Table 5: Reported complications related to neurosurgical intervention

\begin{tabular}{|l|cc|}
\hline Complication & Number & $\%$ \\
\hline Superficial wound infection & 3 & 10.7 \\
CSF leak & 0 & 0 \\
Meningitis & 0 & 0 \\
Abscess & 0 & 0 \\
Reoperation & 2 & 7.1 \\
\hline
\end{tabular}

\section{Discussion}

This paper describes a group of patients who had been involved in war-related penetrating head injury in Syria during March and April 2013. The author's approach was to do a traditional full debridement of necrotic brain, with removal of all accessible bone fragments and foreign bodies. All efforts were done to reconstruct the dura and close the wound tightly. A literature comparison is made between two different approached. Minimalists ${ }^{(8,9,12)}$ and others prefer limited repair of injury, while those following traditional $\operatorname{approach}^{(4,18)}$ used what the author was following. A summary of comparison between both approaches results is presented in table 6 .

Table 6: Comparison between results of minimalists and traditional advocates

\begin{tabular}{|c|c|c|c|c|c|c|c|c|c|}
\hline & & 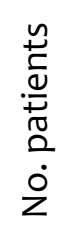 & 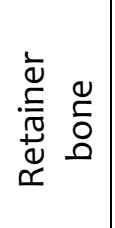 & 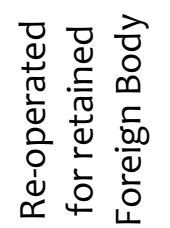 & 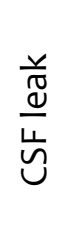 & 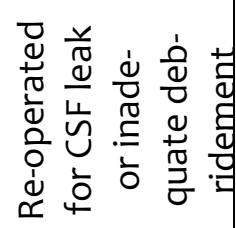 & 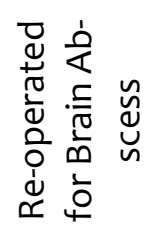 & 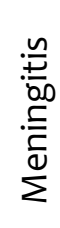 & 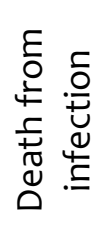 \\
\hline \multirow{3}{*}{ : } & $\begin{array}{l}\text { Taha, } 1991 \\
\text { "Lebanon"(12) }\end{array}$ & 32 & 20 & 0 & 0 & 0 & 1 & 0 & 0 \\
\hline & $\begin{array}{l}\text { Bandvold, } 1990 \\
\text { "Isreal"" }\end{array}$ & 103 & 22 & 0 & $\begin{array}{l}2 \\
9\end{array}$ & 2 & $?$ & 10 & 3 \\
\hline & $\begin{array}{l}\text { Amirjamshidi, } 2003 \\
\text { "Iran"(9) }\end{array}$ & 99 & 99 & 0 & $?$ & 62 & 0 & 5 & 5 \\
\hline \multirow{3}{*}{ 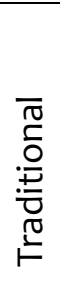 } & $\begin{array}{l}\text { Carey, } 1974 \\
\text { "Vietnam" }\end{array}$ & 99 & 16 & 16 & 2 & 2 & 1 & 2 & 2 \\
\hline & $\begin{array}{l}\text { Aarabi, } 1987 \\
\text { "Iran"(4) }\end{array}$ & 109 & 27 & 0 & 3 & 3 & 2 & 6 & 2 \\
\hline & $\begin{array}{l}\text { Current study, } 2013 \\
\text { "Syria" }\end{array}$ & 28 & $?$ & 1 & 0 & 0 & 0 & 0 & 0 \\
\hline
\end{tabular}




\section{Bone fragments and foreign bodies}

The remaining bone fragments within the injured brain could lead to higher risk of infection. Campbell ${ }^{(19)}$ studied 100 brain injuries and found 17 post-debridement abscesses. All of them contained bone or metal fragments. When in-driven bone fragments were removed completely, infections were $4 \%^{(19)}$, while when these fragments were left behind, $40 \%$ infection rate was found ${ }^{(20)}$. Later on, some authors $^{(9,8,12,21)}$ reported that brain abscess did not result solely from in-driven bone fragments, but other risk factors should be present. This made many neurosurgeons to begin discounting the importance of removing all retained bone. Meanwhile, Aarabi's data ${ }^{(4)}$ suggested that after thorough debridement, 5 individuals (4\%), harbored contaminated bone, yet none of them needed to be operated upon. One may conclude that the defense mechanisms of the patient aided by antibiotics can sterilize these small bits of retained bone fragments within the brain. In a later study, by Aarabi et al ${ }^{(16)}$ of infections in 964 brain wounds, univariate analysis indicated that retained bone fragments had a highly significant bearing on later infection, but this relation was unsustained with use of multivariate analysis.

Brandvold et al $^{(8)}$ studied 43 surviving Israeli soldiers from Lebanon war and found that 22 had evidence of retained bone fragments. These had been well tolerated without evidence of infection. Taha $J M$ et al $^{(22)}$ analyzed 30 patients who had post-debridement infections during the Israel-Lebanon war. Thirteen of these patients had minimal surgery, and the dura was not closed in 23 of them. Twenty-one percent of patients with retained bone fragments developed an infection, while $1.8 \%$ without retained bone became infected. The current study showed $0 \%$ of infection, during the short time period of follow- up. Later follow up may reveal some cases of infection. The conclusion is that even with a small wound; in-driven bone fragments may become contaminated or colonized later by microbes. The failure of some statistical evidence ${ }^{(16,22)}$ to support a connection between in-driven bone fragments and infection may reflect some reduction of infection with early debridement and the use of antibiotics. Some evidence ${ }^{(4,9,8)}$ suggests that later, after missile wounds, small bits of retained bone may pose little treats.

CSF Leakage: Carey et al., in their study ${ }^{(18)}$, found that 2 of 99 patients developed a CSF leak and died. When dura is closed in a watertight fashion, only 3 of 108 patients from Iran developed CSF leakage ${ }^{(4)}$. Several studies $^{(16,22)}$ showed that CSK leakage after brain debridement increases the morbidity and mortality, and should be prevented. Back to minimalists, we found Taha et al., ${ }^{(12)}$ achieved excellent results in his $32 \mathrm{pa}-$ tients who had minor brain wounds and had been debrided and closed in the emergency department. No one developed a CSF leak. In the study by Brandvold et al., ${ }^{(8)}$ with inattention to dural closure, they had 29 CSF leaks from a total of 113 patients. Ten patients subsequently developed meningitis. Three died from this complication. Amirjamshidi's minimal debridement technique in 99 patients resulted in death of 5 from CSF leak ${ }^{(9)}$. We did not have any patients with post-operative CSF leak. We were very careful regarding the meticulous closure of the dura with use of pericranium or temporalis fascia flap.

Re-operation: In this study, two patients needed reoperation. The first one (presented in figure 1) had the penetration at the right frontal area and the foreign body crossed the midline to stay at the left occipital region. During the first operation, full debridement, removal of bone chips and tight dura closure was done. An attempt 
had been made to remove the foreign body at the same session, but intracranial pressure was so high, that opening the dura to remove it was critical. One week later another surgery was done to remove the foreign body successfully, ICP was not high. The second male patient (7 years old) had a bullet entering from the vertex to the posterior fossa (Figure 4). His initial GCS was 8/15. Initial CT showed small supratentorial non-surgical hematoma. Posterior fossa bony decompression was done and the bullet that was found extradural was removed. The vertex penetration was closed simply. Three hours later, the patient deteriorated to GCS of 5/15. As CT was not available, the entry wound was re-explored and a deep and large intracerebral hematoma was evacuated. A possible sinus injury might be the cause, and ultra-early $C T$ brain missed the hematoma that developed later. Unfortunately, the patient died.

Looking again to the literature; 18 of Carey's 99 patients required reoperation: 15 for removal of bone chips, 2 for treating CSF leak, and 1 for abscess ${ }^{(18)}$. Aarabi's reoperated for 5 patients out of 108: 3 for CSF leakage, and 2 for brain abscess ${ }^{(4)}$. Some minimalist reported low reoperation rates: Taha ${ }^{(12)}$ reoperated on 1 of 32 patients, Brandvold ${ }^{(8)}$ re-operated on 2 of 103 patients. On the other hand Amirjamshidi's study ${ }^{(9)}$, showed the need for reoperation for 62 of 99 patients for CSF leakage or inadequate wound debridement.
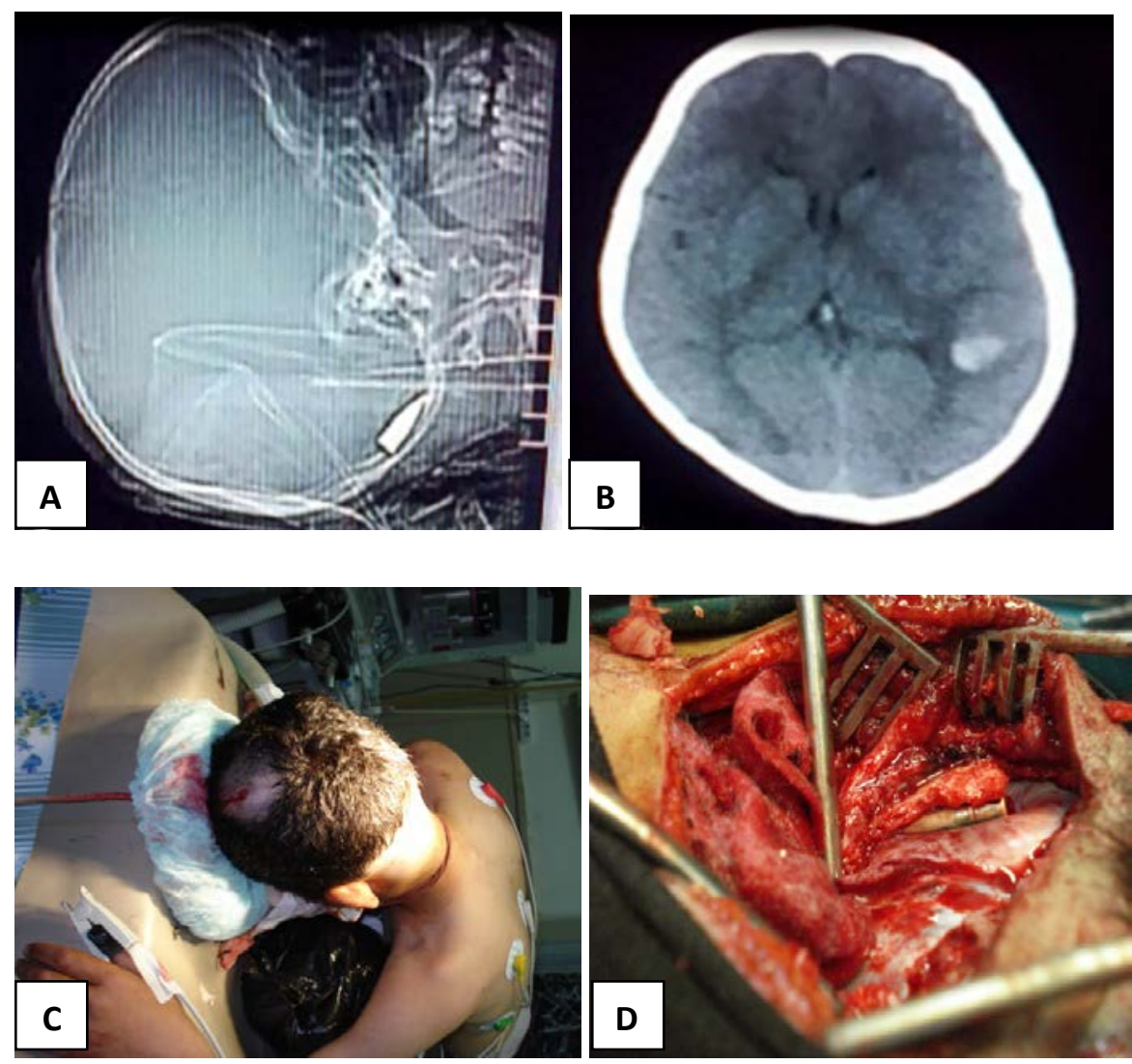

Figure 4: A male child aged 7-years old had bullet injury entering the vertex and staying at the posterior fossa. Scout film on CT showed the bullet site (A). Small nonsurgical hematoma at the track of the bullet was evident on axial CT image (B). The patient had been operated to decompress the posterior fossa and remove the bullet and to avoid further brainstem compression by a possible edema (C). Intraoperative image show-ed the location of the bullet in the extradural space (D). The patient had deteriorated due to expansion of the small intracerebral hematoma, which was evacuated, but the patient died.

\section{Conclusions}

The two extreme sides of surgical management of penetrating war-related injury to the brain are between very minimal scalp closure in the emergency department, to the other extreme with debride- 
ment of all devitalized tissues and removal of all bone fragments and foreign bodies, and water-tight closure of the dura, and thorough repair of the scalp. Based on our results and review of literature, minimal brain debridement without attention to close the dura is more likely to require an additional debridement. This may result in higher incidence of life-threatening CSF leak and I fatal meningitis.

\section{References}

1. Rosenfeld JV, McFarlane AC, Bragge $P$, Armonda RA, Grimes JB, Ling GS. Blastrelated traumatic brain injury. Lancet Neurol, 2013; 12 (9): 882-893.

2. Maqnuson J, Leonessa F, Ling GS. Neuropathology of explosive blast traumatic brain injury. Curr Neurol Neurosci Rep, 2012; 12(5): 570-579.

3. Cushing $\mathrm{H}$. Notes on penetrating wounds of the brain. Br Med J, 1918 (2982); 1:221226.

4. Aarabi B. Comparative study of bacteriological contamination between primary and secondary exploration of missile head wounds. Neurosurgery, 1987; 20 (4): 610-616.

5. Carey ME, Young HF, Mathis JL. The neurosurgical treatment of craniocerebral missile wounds in Vietnam. Surg Gynecol Obstet, 1972; 135 (3): 386-389.

6. Hammon WM. Analysis of 2187 consecutive penetrating wounds of the brain from Vietnam. J Neurosurg, 1971; 34 (2Pt1): 127-131.

7. Aarabi B. Surgical outcome in 435 patients who sustained missile head wounds during the Iran-Iraq war. Neurosurgery, 1990; 27 (5): 692-695.

8. Brandvold B, Levi L, Feinsod M, George ED. Penetrating craniocerebral injuries in the Israeli involvement in the Lebanese conflict, 1982-1985. Analysis of a less aggressive surgical approach. J Neurosurg, 1990; 72 (1): 15-21.

9. Amirjamshidi $A$, Abbassioun $\mathrm{K}$, Rahmat $\mathrm{H}$. Minimal debridement or simple wound closure as the only surgical treatment of war victims with low-velocity penetrating head injuries. Indications and management protocol based upon more than 8 years follow-up of 99 cases from the Iran-Iraq conflict. Surg Neurol, 2003; 60 (2): 105-110.

10. Rahimi-Movaghar $V$, Jazayeri SB, Alimi $M$, Abbassioun K, Amirjamshidi A. Lessons learned from the war: a comprehensive review of the published experiences of the Iranian neurosurgeons during the Iraq-Iran conflict and review of the related literature. World Neurosurg, 2013; 79 (2): 346-358.

11. Carey ME. The treatment of wartime brain wounds: traditional versus minimal debridement. Surg Neurol, 2003; 60 (2): 112-119

12. Taha JM, Saba MI, Brown JA. Missile injuries to the brain treated by the simple wound closure: results of a protocol during the Lebanese conflict. Neurosurgery, 1991; 29 (3): 380-383.

13. American College of Surgeons Committee on Trauma. ATLS (Advanced Trauma Life Support) for Doctors Students Manual. $8^{\text {th }}$ Ed. Chicago: American College of Surgeons, Chicago 2008.

14. Grahm TW, Williams FC Jr, Harrington T Spetzler RF. Civilian gunshot wounds to the head: A prospective study. Neurosurgery, 1990; 27 (5): 696-700.

15. Temkin NR. Preventing and treating posttraumatic seizures: The human experience. Epilepsia, 2009; 50 (Suppl 2): 1013.

16. Aarabi B, Taqhipour M, Alibaii E, Kamqarpour A. Central nervous system infections after military missile head wounds. Neurosurgery, 1998; 42 (3): 500507.

17. Karnofsky DA, Burchenal JH. The clinical evaluation of chemotherapeutic agents in cancer. In Macleod CM, (Ed). Evaluation of chemotherapy agents. Columbia University Press, New York, 1949, 191205.

18. Carey ME, Young HF, Rish BL, Mathis JL. Follow-up study of 103 American soldiers who sustained a brain wound in Vietnam. J Neurosurg, 1974; 41 (5): 542-549. 
19. Campbell EH. Compound, comminuted skull fractures produced by missiles: report based upon 100 cases. Ann Surg, 1945; 122 (3): 375-397.

20. Martin J, Campbell EH Jr. Early complications following penetrating wounds of the skull. J Neurosurg, 1946; 3:58-73

21. Aarabi B. Causes of infections in penetrating head wounds in the Iran-Iraq war. Neurosurgery, 1989; 25 (6): 923-926.

22. Taha JM, Haddad FS, Brown JA. Intracranial infection after missile injuries to the brain: report of 30 cases from the Lebanese conflict. Neurosurgery, 1991; 29 (6): 864-868. 